\title{
Ethics-related guidelines for authors and article retractions: How do Indian biomedical journals measure up?
}

\section{MADHAVI BHARGAVA, VINA VASWANI, RAVI VASWANI}

\begin{abstract}
Background: There has been an increase in research output from India, which in turn has led to an increase in the number of Indian journals facilitating biomedical research. The instructions to authors in the websites of these journals should clearly display ethics-related guidelines for the ethical publication process. The present study did an objective assessment of "instructions to authors" on the websites of Indian biomedical journals in PubMed and IndMED and retractions in these journals from January 2012 to October 2017.
\end{abstract}

Methods: A 14-point checklist based on previous studies and review of literature was used. A total of 110 journals were included in the study and their websites assessed.

Results: A dedicated section on ethics was found in 56 (50.9\%) journal websites, 42 (38.2\%) did not mention any specific bioethics guidelines, animal ethics was mentioned in 65 (59\%) of the journals, and an ethics committee approval was required by 65 (59\%) of the journals. Sixty-four (58.2\%) journals mentioned mandatory informed consent and 19 (17.3\%) required assent. There were 22 (20\%) journals that required neither Clinical Trial Registry of India (CTRI) registration nor Consolidated Standards of Reporting Trials (CONSORT) guidelines for reporting of clinical trials. There were 38 (34.5\%) journals that actively looked for plagiarism. Most common reason for retraction was duplicate publication $(23,38.4 \%)$ followed by plagiarism $(17,28.3 \%)$.

\footnotetext{
Authors: Madhavi Bhargava (corresponding author - madhavi.bhargava@ yenepoya.edu.in), Assistant Professor, Dept of Community Medicine, Yenepoya Medical College, and Deputy Head, Center for Nutrition Studies, Yenepoya (deemed University), Mangaluru,575 018 INDIA; Vina Vaswani (bioethics@yenepoya.edu.in),Professor and Head, Dept of Forensic Medicine and Director Centre for Ethics, Yenepoya Medical College, Yenepoya (deemed to be University),Mangaluru,575 018 INDIA; Ravi Vaswani (ravi. vaswani@yenepoya.edu.in), Professor, Dept of Internal Medicine, Yenepoya Medical College, Faculty, Centre for Ethics, Yenepoya (deemed to be University), Mangaluru,575 018 INDIA.

To cite: Bhargava M, Vaswani V, Vaswani R. Ethics-related guidelines for authors and article retractions: How do Indian biomedical journals measure up? Indian J Med Ethics. 2020 Jan-Mar; 5(1) NS: 25-33. DOI:10.20529/ IJME.2019.076.

Published online on November 25, 2019

Manuscript Editor: Sanjay A Pai

Peer Reviewers: Joe Varghese and an anonymous reviewer

OIndian Journal of Medical Ethics 2020
}

Conclusion: The lacunae found in this survey indicate a need for strengthening of author instructions. The number of retractions in the last five years suggests that there are valid reasons to strengthen ethics in the publication process in India.

\section{Introduction}

Publication in medical science is important for several reasons. Some of these reasons include sharing discoveries, knowledge, recognition, or assessment in the field of work, and as a requirement for acquiring a degree or even promotion $(1,2)$. While publishing is a matter of prestige, it also facilitates a deeper understanding of the subject and promotes further ideas which can lead to scientific advancement in the respective fields (3). This has led to an increase in the number of journals and the amount of research that is being done and published in India and abroad. Most journals have guidelines on their websites for a smooth submission and publication process.

Guidelines or instructions to authors on these websites need to be explicit and regularly updated for an ethical publication process. A clear, unambiguous public display of zero tolerance towards an unethical research and publication process would serve as a gatekeeper to good quality research output. This includes recommendations for ethical clearance from the respective institutional review boards, registration of trials in standard registries, participant confidentiality and autonomy, and authorship guidelines, to name a few.

There has been increasing interest in the assessment of journal websites on the basis of author instructions and an ethical publication process. This type of assessment has been done in the past for a limited number of journals, or specialties (4-7). It has not been done across specialties and across major databases. In a retrospective analysis of articles published in Indian paediatrics journals, ethics committee approval was not declared in 93 (70.5\%), and 52 of 96 (53\%) papers that required consent from parents/guardians did not report obtaining the required consent. In 44 of 98 studies on children older than 7 years, eight reported obtaining consent (5). Another study looked at seven aspects in 100 Indian biomedical journals: ethics heading, ethics approval, informed consent, assent, following the Declaration of Helsinki or following the National Ethical Guidelines, and approval of an animal ethics committee (4). The aspect least found was assent (3 journals) followed by approval of animal ethics committee ( 27 journals). Ethics approval was required by 62 journals, and 43 required 
informed consent. Jaykaran et al looked at 59 Indian journals compiled from Google, PubMed, and National Informatics Centre and looked at authorship, ethics committee approval, informed consent, assent, and research from the point of view of the Indian Council of Medical Research or Declaration of Helsinki guidelines (7).

In the present study the authors carried out an objective assessment of "instructions to authors" on the websites of Indian journals included in PubMed and IndMED. In addition, the number of retractions and reasons for retractions from January 2012 till October 2017 were assessed.

\section{Methodology}

The author (MB) conducted a survey of websites of Indian journals in IndMED (8) and PubMed with respect to "instructions to authors." A 14-point checklist was prepared based on previous studies (4-7), a preliminary review of instructions to authors by some journals, and relevant review of literature. The articles withdrawn in the last five years (January 2012 to October 2017) were also identified and reasons for withdrawal assessed. Key words such as "retraction", "withdrawal", "corrigendum", and "erratum" were used in PubMed. For articles in IndMED, each issue was hand-searched to look for retractions. The reasons for such retraction were then listed.

\section{Inclusion criteria}

Medical journals belonging to modern medicine were included.

1. Indian journals included in IndMED, PubMed or both

2. Articles withdrawn during the period from January 2012 to October 2017

\section{Exclusion criteria}

Journals with no website, journals without any kind of author instructions, and periodicals were excluded from the study. Journals belonging to alternative medicine, such as Ayurveda, Siddha or Unani, were also excluded due to lack of clarity with regard to applicability of research and publication ethics in these disciplines. Moreover, the knowledge and background of the authors limited their expertise in this area to make any judgement.

\section{"Indian journal"}

For the purpose of this survey, an "Indian journal" is one which is managed by a professional body in India (not all journals which are published from India were included in the assessment).

The list of journals thus shortlisted was checked against list of predatory journals (Beall's list of predatory journals as on December 2017), and it was confirmed that none of the

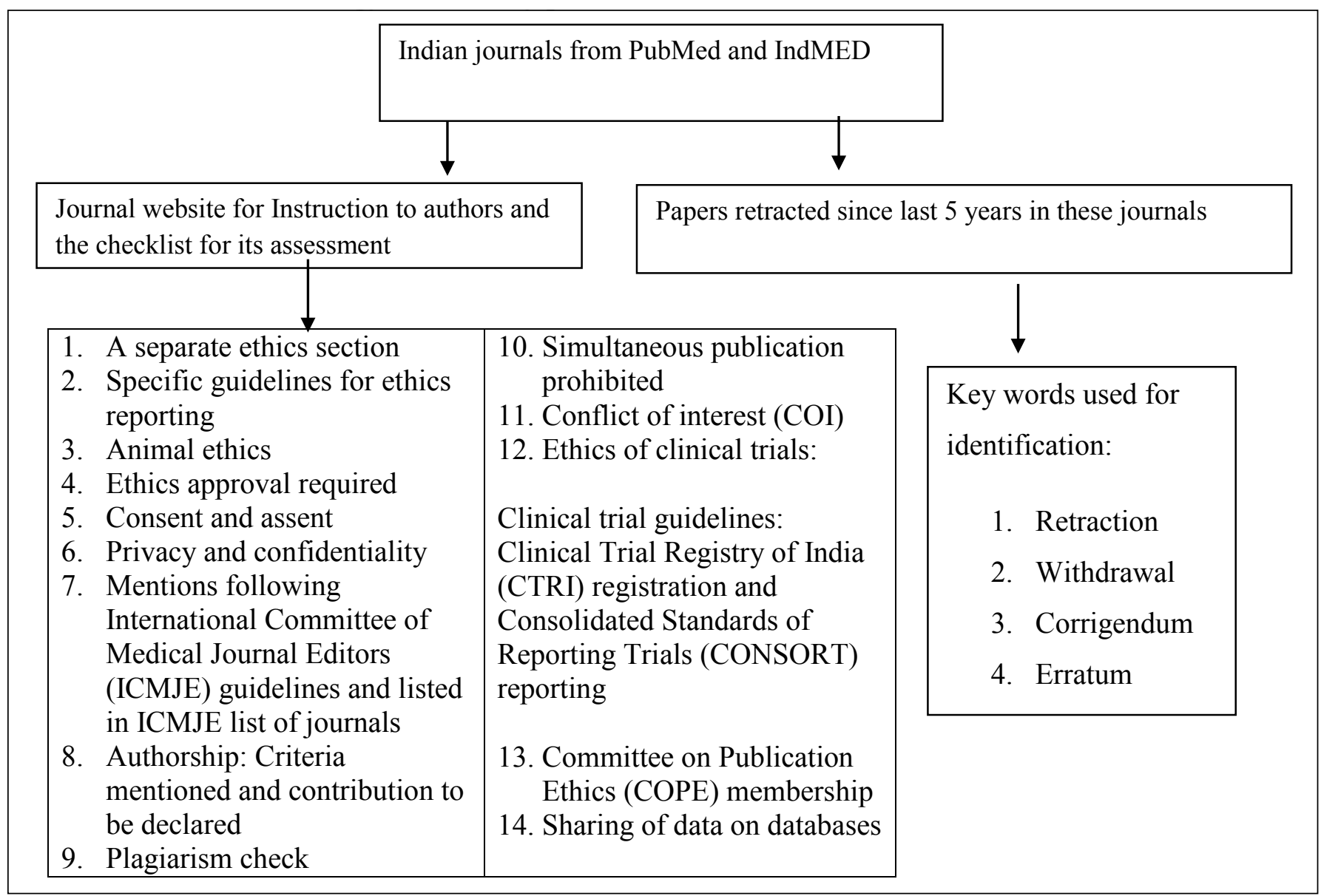

Figure 1: Methodology of the study process: 
journals shortlisted belonged to it.

\section{Results}

A total of 129 Indian journals were shortlisted using the IndMED website and PubMed National Library of Medicine catalogue of journals. Of these, 110 journals had accessible websites with clear author instructions and were included in

\begin{tabular}{|l|l|c|}
\hline \multicolumn{3}{|c|}{ Table 1: Characteristics of Journals included in the study } \\
\hline Characteristics of journal included (N = 129) & Number (\%) \\
\hline \multirow{2}{*}{ Database } & PubMed only & $26(20.2)$ \\
\cline { 2 - 3 } & IndMED only & $37(28.7)$ \\
\cline { 2 - 3 } & PubMed and IndMED & $66(51.2)$ \\
\hline Included in PubMed ( $\mathrm{n}=92)$ & Presently in PubMed & $70(76.1)$ \\
\cline { 2 - 3 } & $\begin{array}{l}\text { Not presently in } \\
\text { PubMed }\end{array}$ & $22(23.9)$ \\
\hline
\end{tabular}

further analysis. Table 1 depicts whether the journal is included in the PubMed or IndMED database.

Table 2 describes the results of the instruction to authors on the journal website. A dedicated section on ethics was found in $56(50.9 \%)$ journals. In the rest of the journals, it was part of the text and not prominently displayed as instructions. Fiftyone $(46.4 \%)$ journals mentioned the Declaration of Helsinki as the guidelines to be followed for articles submitted to them. Ten (9\%) journals mentioned the Indian Council of Medical Research guidelines as the only guideline and seven (6.4\%) journals mentioned both. Forty-two (38.2\%) journals did not provide any specific guidelines for research and publication ethics. Animal ethics was mentioned in 65 (59\%) of the journals. Ethics committee approval was required by 65 (59\%) of the journals.

Regarding patient autonomy, 64 (58.2\%) of the journals mentioned that informed consent was mandatory for human participants, and only 19 (17.3\%) of the biomedical journals studied mentioned assent. The importance of privacy and confidentiality of the human participants was conveyed in 61 (55.5\%) of the journals. While $73(66.4 \%)$ journals mentioned following the International Committee of Medical Journal Editors (ICMJE) guidelines for publication, only 34 (31\%) of these journals were actually listed in the ICMJE list of journals.

With regard to clinical trials, registration of the trial in the clinical trial registry of India as a requirement was mentioned in $36(32.7 \%)$ of the journals and reporting of trials according to Consolidated Standards of Reporting Trials (CONSORT) was required by 52 (47.3\%) of the journals. There were 22 (20\%) journals where the instructions to authors did not require either Clinical Trial Registry of India (CTRI) registration or the requirement of CONSORT guidelines for reporting of clinical trials. There were 38 (34.5\%) journals that actively looked for plagiarism and explicitly mentioned it on the website along with a warning about action against authors if found guilty of plagiarism.
Table 2: Instructions to authors towards ethical publication process

\begin{tabular}{|c|c|c|c|}
\hline \multirow{3}{*}{\begin{tabular}{|l|} 
No. \\
1. \\
\end{tabular}} & \multicolumn{2}{|c|}{$\begin{array}{l}\text { Specific instructions }(\mathrm{N}=110 ; 19 \text { journals } \\
\text { had no author instructions accessible on their } \\
\text { websites) }\end{array}$} & \multirow{2}{*}{$\begin{array}{c}\begin{array}{c}\text { Number } \\
\text { (\%) }\end{array} \\
56(50.9) \\
\end{array}$} \\
\hline & Separate ethics section & Yes & \\
\hline & & No & $54(49.1)$ \\
\hline \multirow[t]{4}{*}{2.} & \multirow{4}{*}{$\begin{array}{l}\text { Any specific guidelines for } \\
\text { ethics being followed }\end{array}$} & ICMR & $10(9)$ \\
\hline & & Declaration of Helsinki & $51(46.4)$ \\
\hline & & Both & $7(6.4)$ \\
\hline & & None & $42(38.2)$ \\
\hline 3. & $\begin{array}{l}\text { Approval of animal ethics } \\
\text { committee }\end{array}$ & Yes & $65(59)$ \\
\hline 4. & $\begin{array}{l}\text { Ethics approval required } \\
\text { for submission }\end{array}$ & Yes & $67(61)$ \\
\hline \multirow[t]{2}{*}{5.} & \multirow[t]{2}{*}{ Consent and assent } & Informed consent & $64(58.2)$ \\
\hline & & Assent requirement & $19(17.3)$ \\
\hline 6. & \begin{tabular}{|l} 
Privacy and \\
confidentiality
\end{tabular} & Yes & $61(55.5)$ \\
\hline \multirow[t]{4}{*}{7.} & \multirow[t]{4}{*}{ ICMJE guidelines } & $\begin{array}{l}\text { Mentions that follows } \\
\text { ICMJE guidelines }\end{array}$ & $73(66.4)$ \\
\hline & & ICMJE listed & $34(31)$ \\
\hline & & $\begin{array}{l}\text { Authorship criteria } \\
\text { mentioned }\end{array}$ & $56(51)$ \\
\hline & & $\begin{array}{l}\text { Author contribution to } \\
\text { be declared }\end{array}$ & $49(44.5)$ \\
\hline 8. & $\begin{array}{l}\text { Actively look for } \\
\text { plagiarism and take } \\
\text { action, if found }\end{array}$ & Yes & $38(34.5)$ \\
\hline 9. & $\begin{array}{l}\text { Simultaneous publication } \\
\text { prohibited }\end{array}$ & Yes & $81(73.6)$ \\
\hline 10. & \begin{tabular}{|l|}
$\begin{array}{l}\text { Conflict of interest } \\
\text { declaration required }\end{array}$ \\
\end{tabular} & Yes & $75(68.2)$ \\
\hline \multirow[t]{3}{*}{11.} & \multirow[t]{3}{*}{ Ethics of Clinical trials } & $\begin{array}{l}\text { CTRI registration } \\
\text { required by the journal }\end{array}$ & $36(32.7)$ \\
\hline & & \begin{tabular}{|l|} 
Manuscript reporting \\
according to CONSORT
\end{tabular} & $52(47.3)$ \\
\hline & & $\begin{array}{l}\text { Instructions mention } \\
\text { neither CTRI nor } \\
\text { CONSORT } \\
\end{array}$ & $22(20)$ \\
\hline 12. & COPE membership & Yes & $18(16.4)$ \\
\hline 13 & $\begin{array}{l}\text { Journals with no author } \\
\text { instructions or proper } \\
\text { website }\end{array}$ & & $19(17.3)$ \\
\hline 14 & Data sharing & Yes & $0(0 \%)$ \\
\hline
\end{tabular}

ICMR: Indian Council of Medical Research; ICMJE: International Committee of Medical Journal Editors; CTRI: Clinical Trial Registry of India; CONSORT: Consolidated Standards of Reporting Trials; COPE: Committee on Publication Ethics

One of the most commonly followed parameters was that of prohibition of simultaneous publication as this was described very clearly in 81 (73.6\%) of the journals. This was followed by the requirement of clarification regarding conflict of interest (COI) statement $(75,68.2 \%)$. Eighteen journals that mentioned that they were members of the Committee on Publication Ethics (COPE).

We categorised the journals according to the extent of fulfillment of the checklist provided earlier. Forty-three (33.3\%) journals fulfilled the minimum of 10 components 
of the checklist, and 68 (62\%) journals had 50\% satisfactory author instructions according to the checklist. The number of journals that had four or even fewer components of the present checklist reflected in their author instructions was 30 (27.3\%). Considering that data sharing was not uniformly part of author instructions, the Journal of Anaesthesiology Clinical Pharmacology, was the only journal which fulfilled all the 13 remaining components of the checklist. This was the only journal that required the name of the ethics committee on the title page along with the name of the member secretary, approval number, date, and institute's name. The Indian Journal of Medical Ethics was the only journal that included the fourth criterion of the authorship criteria recently added in the ICMJE. Indian Journal of Nephrology was the only journal that required ethics clearance even for retrospective studies. Informed consent for most journals was in the context of clinical photographs. Indian Journal of Physiology and Pharmacology, which publishes many drug trials, does not mention a CTRI requirement in its author instructions. Biomedicine, a journal of the Indian Association of Biomedical Scientists, which is included in IndMED and describes itself as approved by the University Grants Commission, has a dedicated "code of ethics" section. But this section was found to have major similarities to the International Journal of Science and Research (IJSR).

Journal of Genetics published by the Indian Academy of Sciences had a very informative and detailed section dedicated to plagiarism and also mentioned self-plagiarism as equally unacceptable.

Table 3 describes the reasons for the 60 retractions that took place from January 2012 till October 2017. The most common reason for retraction was duplicate articles, (23, $38.4 \%)$, followed by plagiarism $(17,28.3 \%)$, which included one article with plagiarism from Wikipedia. Some of the other reasons for retraction were authorship issues and "inadvertent publication."

\section{Discussion}

Our study attempts to assess the preparedness of biomedical journals from India in PubMed and IndMED for the ethical publication process. Inclusion of a journal in databases like PubMed and IndMED facilitates accessibility, increases readership, and may reflect quality to some extent $(8,9)$. IndMED is an ICMR-funded project that supplements the international PubMed service for select peer-reviewed Indian medical journals (8). Nineteen journals are included in the IndMED but do not have traceable author instructions. The Journal of the Association of Physicians of India, which is currently Medline-indexed, has a functioning website and submission page but no traceable author instructions. The Nursing Journal of India published by the Trained Nurses' Association of India (no longer indexed in Medline) shows issues till date on its website but no author instructions. Only $33 \%$ of the journals fulfilled at least 10 of the 14 components of the checklist used by the authors to assess the completeness of author instructions from the ethics point of view.

We discuss the findings of the study as per the checklist used.

\section{Separate section in ethics and specific guidelines for ethics}

A separate section dedicated to ethics is indicative of the importance given to the ethical research and publication process by the journal. This was found in the website of roughly half of the journals surveyed. More than half mentioned the Declaration of Helsinki as specific guidelines to be followed. In a recent study, $71 \%$ mentioned the Declaration of Helsinki, but only $15 \%$ referred to the latest amendments. The rest referred to the older versions (10). The absence of the near ubiquitous reference to ICMR guidelines in Indian journals was striking. This could be because the more recent ICMR guidelines were in the draft phase when the data collection was done for this study (11).

\section{Approval of animal ethics committee}

Animal ethics found a place in the instructions to authors in less than $60 \%$ of the journals. This could be because some of these journals may not be publishing research on animals often. But since they do not explicitly state that no animal studies will be published in the journal, it is required that they mention animal ethics. The instructions to authors have an educational value in disseminating principles of biomedical ethics to the scientific community, animal ethics should find a place in the author instructions (10). The Committee for the Purpose of Control and Supervision of Experiments on Animals (CPCSEA) is a statutory body formed by an Act of the Indian Parliament under the Prevention of Cruelty to Animals Acts and is the one most commonly mentioned by journal websites (12). The Indian National Science Academy (INSA) guidelines (1992 and 2000; in 2000, genetically modified animals were included) were mentioned in five journals. In a study by Atlas et al in 2003, 124 high impact journals were assessed on their instructions to authors. Only 40 journals included some type of guideline concerning protection of experimental animals (13). In another study involving 59 Indian medical journals, approval from an animal ethics committee was mentioned only in 10 journals (7).

\section{Ethics approval as a requirement}

In the present study, $61 \%$ of the journals required ethics approval for research publication. The mere absence of mention of ethics clearance does not mean that the research published in these journals is unethical (14). It could be due to lack of space, need to report competing content of the research work, or absence of such a requirement specified in the journal guidelines. Forty three out of 110 journals did not state a requirement for mandatory ethics approval, and this might be perceived as encouraging "opacity" (as opposed to "transparency") or not considering ethical review for publication which is important in the publication process. A study was conducted to assess reporting practice of ethics approval in four Indian journals, namely The Journal of the Association of Physicians of India (JAPI), Indian Journal of Surgery (IJS), Journal of 


\begin{tabular}{|c|c|c|c|c|c|}
\hline \multirow[t]{2}{*}{ Journal name } & \multirow{2}{*}{$\begin{array}{l}\text { Number } \\
\text { retracted }\end{array}$} & \multicolumn{4}{|c|}{ Reasons for retraction } \\
\hline & & Duplicate & Plagiarism & $\begin{array}{l}\text { Simultaneous } \\
\text { submission }\end{array}$ & Others \\
\hline Journal of Minimal Access Surgery & 1 & 1 & & & \\
\hline Indian Journal of Pediatrics & 3 & & 1 & & $\begin{array}{l}\text { - Authors requested as the data got } \\
\text { mixed up } \\
\text { - Copyright issues }\end{array}$ \\
\hline Indian Journal of Experimental Biology & 1 & & & & Reasons not known \\
\hline $\begin{array}{l}\text { Indian Journal of Dermatology, Venereology, and } \\
\text { Leprology }\end{array}$ & 2 & 1 & & & $\begin{array}{l}\text { Patient family revoked the permission } \\
\text { due to privacy issues }\end{array}$ \\
\hline Indian Journal of Pathology and Microbiology & 2 & & & & Reasons not known \\
\hline Indian Journal of Psychiatry & 1 & 1 & & & Plagiarism (from Wikipedia) \\
\hline Neurology India & 1 & & & & Reasons not known \\
\hline Indian Journal of Community Medicine & 4 & 4 & & & $\begin{array}{l}\text { Two articles of same kind published } \\
\text { twice, thus all four retracted }\end{array}$ \\
\hline Diabetes and Metabolic Syndrome & 1 & & & & Reasons not known \\
\hline Journal of Cancer Research and Therapeutics & 2 & 2 & & & \\
\hline Indian Journal of Dental Research & 3 & & 3 & & \\
\hline $\begin{array}{l}\text { Journal of the Indian Society of Pedodontics and } \\
\text { Preventive Dentistry }\end{array}$ & 2 & 2 & & & \\
\hline Indian Journal of Urology & 2 & 1 & 1 & & \\
\hline Indian Journal of Plastic Surgery & 1 & & & & 1 \\
\hline Annals of Cardiac Anaesthesia & 2 & & & & No reasons clearly mentioned \\
\hline Indian Journal of Public Health & 1 & & & & $\begin{array}{l}\text { Inadvertent publication (reason not } \\
\text { clearly mentioned) }\end{array}$ \\
\hline Indian Journal of Dermatology & 8 & 4 & 2 & 2 & $\begin{array}{l}\text { Out of these, two were triplicate } \\
\text { submission, } \\
\text { one was plagiarised from thesis }\end{array}$ \\
\hline Indian Journal of Surgery & 1 & & & & Copyright issues \\
\hline Journal of Parasitic Diseases & 2 & & 1 & & \\
\hline Journal of Anaesthesiology Clinical Pharmacology & 2 & 1 & 1 & & \\
\hline Journal of Indian Society of Periodontology & 4 & 1 & 1 & & $\begin{array}{l}\text { Misrepresentation of facts, } \\
\text { no permission of co-authors was } \\
\text { taken before publication }\end{array}$ \\
\hline Journal of Human Reproductive Sciences & 3 & & 3 & & \\
\hline $\begin{array}{l}\text { Journal of Indian Society of Pedodontics and } \\
\text { Preventive Dentistry }\end{array}$ & 1 & 1 & & & \\
\hline Contemporary Clinical Dentistry & 6 & 4 & 2 & & \\
\hline Indian Journal of Anaesthesia & 1 & & 1 & & \\
\hline Indian Journal of Clinical Biochemistry & 1 & & & & $\begin{array}{l}\text { Inclusion of author without } \\
\text { permission/information }\end{array}$ \\
\hline Indian Journal of Medical and Pediatric Oncology & 1 & & & & $\begin{array}{l}\text { Mistake in including name of } \\
\text { an author who had made no } \\
\text { contribution }\end{array}$ \\
\hline Medical Journal Armed Forces India & 1 & & 1 & & \\
\hline Total & 60 & $\begin{array}{c}23 \\
(38.4 \%)\end{array}$ & $\begin{array}{c}17 \\
(28.3 \%)\end{array}$ & $\begin{array}{c}2 \\
(3.3 \%)\end{array}$ & $\begin{array}{l}18 \\
(30 \%)\end{array}$ \\
\hline
\end{tabular}

Obstetrics and Gynecology of India (JOGl), and the Indian Journal of Orthopaedics (IJO). A total of 673 articles were reviewed, of which a mere 163 (24\%) reported ethics approval (6).

\section{Consent and assent}

Participant consent in the form of an informed consent was a requirement in $58 \%$ of the journals. This requirement has many finer points that are usually not mentioned in the journal instructions to the authors but have been described in detail in the Declaration of Helsinki (15). Here, after ensuring that the participant has understood the information, the investigator should preferably take a written informed consent and, when this is not possible, formally document the nonwritten consent with a witness. Moreover, it is very important that the physician-investigator identifies a dependent relationship where consent may not be entirely voluntary. The present study found that many journals which require informed consent confine this requirement only to clinical 
photographs. But informed consent to explain the full extent of the participant's involvement is required in any study which involves humans, and not just for clinical photographs.

A study done by Asai and Singu in 1999 found that eight out of 11 anaesthesiology journals from Science Citation Index Journal Citation Report, had mentioned informed consent as a requirement which was a marked improvement as compared to that in 1995 (16). In a study by Belhekar in 2014, 673 research articles were reviewed from JAPI, IJS, JOGI, and IJO (6). Overall, $26.5 \%$ articles mentioned informed consent, of which IJS fared the worst (16.2\% articles mentioning informed consent), followed by JAPI (39\% of articles). In 2011, a survey of 59 Indian journals (selected from PubMed, Google, and National Informatics Centre) found that $74.5 \%$ journals mentioned the requirement of informed consent (7). In 2017, a similar survey in 55 Indian journals included in PubMed found that reporting whether consent was obtained for enrolment in a study was recommended by $47.3 \%$ of the journals. This study identified the phrases that were used for consent: "consent" $(n=1)$; "informed consent" $(n=23)$; and "written consent" $(n=2)$ (10). A very insightful qualitative study in Kenya explored the community's views on the consent process during a time when three research studies were being conducted in a rural area (17). It was found that the community was confused and could not distinguish between clinical investigations and research, suggesting therapeutic misconception.

Only $17 \%$ of the journals required assent. While it is possible that not all journals deal with the paediatric population, it can be argued that these journals also do not have any policy regarding refusal of original research in paediatric population and, hence, need to address assent in their submission guidelines. Similar findings have been noted in the past; in one study only nine out of 59 (15.2\%) Indian medical journals had assent as a requirement and in another it was $18 \%(7,10)$. According to the Declaration of Helsinki, when a potential research subject is incapable of informed consent, assent should be taken along with the consent of the legally authorised representative (15). The ICMR (2006) guidelines mention the requirement of assent of a child who is a mature minor and state the required age as 7-18 years of age, and the recently updated ICMR guidelines add that oral assent is required for ages 7-12 and written for ages 13-18 (11). The age at which this informed assent should be taken varies, but the researchers should consider asking for assent from children over the age of 7 years and take it from all children over the age of 12 years (18). In a study in 2008, 132 research articles from two Indian paediatric journals were examined for ethical issues. A total of 54 articles had children of 7 years or more and were required to report assent, but only eight (15\%) reported children's assent (5). The problem thus seems relevant even in those journals specifically addressing the vulnerable paediatric population. Moreover, the instructions to authors are educational for young researchers and can serve as a medium to highlight the importance of assent; so the importance of assent should find a place in instructions to authors of all journals.
In the debate around the need for assent, Baines states that "if consent is the authority to proceed, then assent has no role" and that it can actually harm (19). But the purpose of an assent is not to provide second consent but to facilitate the child's involvement in the decision-making process (20). The three important ethical arguments used for assent are: children's rights, the best interest of the child, and respect and facilitation of the child's developing autonomy, which has future implications. As Sibley explains, there is a two-fold justification: "respect for the parent's pedagogical role in teaching their child to become autonomous and respect for child's moral worth." The latter basically means listening, considering, engaging, and involving children in the decision-making process (20).

\section{Privacy and confidentiality}

Protection of privacy and confidentiality of the research participant was mentioned in $55.5 \%$ of the journals in their author instructions. Most journals mention protection of privacy and confidentiality in the context of clinical photographs, whereas privacy and confidentiality actually have relevance beyond just photographs. Privacy is a person's interest in controlling access to himself or herself. Apart from the physical, such privacy can also be informational. Confidentiality deals with informational privacy. Information in this context includes a medical condition, income details, and personal habits, among other things. In terms of physical privacy, it can be body part examination, a biological specimen, and related personal space. Accessing medical records, for example, can be invasion of informational privacy. While both are important in clinical as well as research settings, it is more important in research settings, where the responsibility for the protection of research subjects is with the researcher and never with the research subject (15). In the study by Asai and Shingu in 1999, the term "privacy" was present in 7 of 11 journals in the Science Citation Index (16).

\section{ICMJE and authorship}

In 1978, some of the editors of medical journals got together and constructed a minimum set of guidelines for formatting requirements. This early document called the Uniform Requirement for Manuscripts (URM) has over the years evolved into the much respected ICMJE guidelines that cover a wide range of quality issues in publication, the most recent edition of which came out in 2016 (21). While more than $66 \%$ of Indian journals in the present study mention that they follow the ICMJE guidelines, which is a very simple process, only $31 \%$ were actually listed in the ICMJE list (22). As ICMJE mentions, being listed does not mean "membership" or "certification" of ICMJE itself, but maintenance of such a list has the potential to promote quality of reporting from medical science (22). Moreover, if a journal is not listed in ICMJE but follows the recommendations, it can be considered a positive aspect. Authorship criteria based on ICMJE were mentioned in $51 \%$, while $45 \%$ required author contribution to be declared. In a similar study in the past, authorship as per the ICMJE was mentioned in 59\% of the Indian journals (7). The ICMJE has recommended four criteria for authorship: 
substantial contribution to conception or acquisition; analysis or interpretation of data; drafting the work or revising itand final approval; and lastly, agreement to be accountable for all aspects of the work's accuracy and integrity (22). This is to safeguard the credit and importance of academic work. This fourth criterion is yet to be included in most Indian journals, and the Indian Journal of Medical Ethics was the only one that had included it in its instructions. There is also a criticism that it has become a ready-made tool for the industry where it may exaggerate the contribution of academic authors and downplay the industry authors in the acknowledgment or contribution by using small print while listing their names (23). Nevertheless, these criteria have been the first to objectivise the requirements, and in the absence of a better benchmark, they serve the purpose.

\section{Plagiarism}

The American Association of University Professors in their statement on plagiarism have defined it as "taking over the ideas, methods, or written words of another, without acknowledgment and with the intention that they be taken as the work of the deceiver, is plagiarism" (24).The proportion of journals looking actively for plagiarism, including mentioning it in author instructions and warning of action against it was $34.5 \%$. That a journal may not mention plagiarism in author instructions but may still look out for it is also a possibility. But when all these instructions are assessed in a holistic manner and in context with other deficiencies in the author instructions, not including it almost suggests not actively looking for it. A common reason for the 134 retractions by BioMed Central journals from 2000-2015 was textual plagiarism (25). In another analysis of more than 2000 retractions in PubMed, 9.8\% were due to plagiarism, and countries with a high incidence were Japan, China, India, Korea, Italy, Turkey, Iran, and France (26). A study from India which assessed the knowledge of plagiarism in 5000 dental professionals found that $43 \%$ had frequently and $30 \%$ had occasionally indulged in plagiarism (27). In a meta-analysis of surveys of scientists admitting to plagiarism, it was found that the pooled estimate of committed plagiarism was $1.7 \%(\mathrm{Cl} 1.2-$ 2.4) and that of witnessed plagiarism was $30 \%$ (Cl 17-46) (28).

\section{Prohibition of simultaneous publication}

The ICMJE's recommendation for the Conduct, Reporting, Editing and Publication of Scholarly Work in Medical Journals (updated December 2017) prohibits simultaneous submission of manuscripts to different journals (21). This was the second most frequently mentioned safeguard (after COI) in journal instructions to authors (74\%). While this has not been studied in detail by past studies on publication ethics, there are case reports where the dates of submission and publication dates suggest that the articles were simultaneously submitted to more than one journal (29).

\section{Conflict of interest declaration}

This was the most common requirement in the websites of the journals surveyed (75\%). According to the new ICMR guidelines, $\mathrm{COI}$ is a set of conditions where professional judgement concerning a primary interest such as participants' welfare or validity of research tends to be unduly influenced by a secondary interest, financial or non-financial (personal, academic, or political) (11). Rowan-Legg et al compared journal instructions between 1995 and 2005 for COI disclosure in 100 biomedical journals from Index Medicus (30). The proportion of journals requiring $\mathrm{COI}$ disclosure increased from $75 \%$ to $94 \%$ in this period. They defined COI disclosure under nine domains: employment or leadership position in commercial firm, employment as consultant for commercial firm, family connection, stock ownership, honoraria, research funding or grant, expert testimony, patents, or other remuneration. It was considered comprehensive when the website mentioned these or more domains. The rest had vague statements that allowed optional compliance (30). While most of the time one thinks of $\mathrm{CO}$ in terms of financial benefit, it could also be academic, personal, conceptual, societal, clinical belief, institutional, and so on (21).

\section{Ethics of clinical trials - CTRI and CONSORT}

The requirement of a trial to be registered in CTRI was mentioned by $33 \%$ of the journals in their instructions to authors, and $47 \%$ of the journals required that the trial be reported according to CONSORT. Almost $20 \%$ of the journals mentioned neither. While CTRI is a registry and CONSORT is a reporting format, both contribute towards ethical conduct and reporting of clinical trials. These are comparable to findings of a study in 55 Indian journals included in PubMed, where CONSORT was required by $58 \%$ of the journals and CTRI registration by $36 \%$ of the journals (10). A study by Rowan-Legg et al found only $37 \%$ of 103 biomedical journals indexed in Index Medicus requiring submission according to CONSORT (30).The CTRI in India was launched in 2007 for free registration of trials. The new ICMR guidelines and the Declaration of Helsinki also make registration mandatory $(11,15)$.The trials may include any intervention such as drugs, surgical procedures, and devices; biomedical, educational, or behavioural research; and public health intervention studies, observational studies, implementation research, preclinical studies of experimental therapeutics, and preventives or AYUSH studies. Many editors of eminent Indian journals also released a statement on the need for CTRI registration of trial manuscripts before publication (31). This is especially important as India is becoming a hub for clinical trials facilitated by Contract Research Organisations (CROs), which make cheaper and faster trials possible (32). Apart from journal author instructions, CTRI registry, and CONSORT for reporting, legal oversight, formal training, and accreditation by the Ethics Committee, research mentorship, transparency, and increasing public understanding of the research are some important interventions for ethical clinical trials in India (33).

\section{Data sharing}

The ICMJE proposes that the authors should share deidentified individual data within 6 months after the publication (34). The method of data sharing should be part of the plan 
when the trial is registered. It has the advantage of preventing selective publication and selective reporting of research findings and possibility of duplication research. While this is a welcome move, there are pros and cons as far as the peer review process is concerned (35). Reviewers have access to the data, which helps the scientific review process, but there is also a possibility of delay due to extra burden of material to be reviewed, leading to reviewer fatigue or if they look to further their own research in the same area (35). This is still a new concept that is yet to become popular with academicians and researchers in India as reflected in the lack of such instructions on journal websites.

\section{Committee on Publication Ethics (COPE) membership}

COPE membership among the journals studied was $16.4 \%$. Membership in COPE shows that a journal follows good standards of publication ethics and practises the principles outlined therein. Journals applying for membership will be assessed for a minimum set of criteria. Journals that are not sufficiently transparent about their business practices will fail to get membership (36).

\section{Retractions}

From the websites assessed, there were 60 articles that were retracted for various reasons from 2012 till 2017. The percentage of articles retracted due to duplicate publication was $38.4 \%$. In five (8\%) instances, there was no specific reason for retraction mentioned by the editor, which is contrary to the COPE guidelines (36). Two more papers mentioned "inadvertently published" as reason for retraction, which does not clearly convey the reason. In a study by Moylan et al, 134 retractions from BioMed Central were analysed. Most adhered to the COPE guidelines, where explicit reasons for retraction were given (25). There were three retractions due to authorship issues in the present study, where either the permission of the author was not taken ( 2 retractions) or author name was included by mistake without his contribution. Retractions due to plagiarism were the second largest category in the present study $(28.3 \%)$, and this is similar to the finding in the study by Moylan et al (25). Another large study that has done a detailed review of 2,047 articles from PubMed, which were retracted till May 2013, found that 21.3\% were due to error, and $67.4 \%$ were due to misconduct, fraud, or suspected fraud (43.4\%), duplicate publication (14.2\%), and plagiarism (9.8\%) (26). In 2016, Springer Nature announced the retraction of 58 articles published by Iran-based authors due to plagiarism and manipulation of peer reviewers and the peer review system (37).

It is not difficult to have comprehensive author instructions, but still not follow the standards of the ethical publication process. There have been many experiments demonstrating the ease of predatory publication. A programme called "SClgen" that could create computer-science papers with realistic graphs, figures, and citations (https://pdos.csail.mit. edu/archive/scigen/), was created. When a paper created thus was presented in an international conference, it was accepted; but later, the hoax was exposed. There is now a freely available software called "SciDetect" that detects automatically generated papers (38). This kind of software is yet to be made available to medical science.

In another experiment in biomedical publishing, a fake paper was concocted by the journal Science with 304 versions on a wonder anti-cancer drug and was submitted to open-access journals. More than half of them accepted the article. Of the 106 journals that performed some review, 70\% accepted the paper. Most reviews focused on the layout, formatting, and language (39).

\section{Strengths and limitations}

There have been studies in the area of publication ethics, but they have usually been limited to some specialties or to limited number of journals or limited areas in publication ethics. This study took into consideration all the earlier studies and made a comprehensive checklist and then assessed all the Indian PubMed and IndMED journals. It is the largest number of author instructions of Indian journals studied so far. But the limitation is that instructions to authors is only one of the means to strengthen he ethical publication process. Journals may have the most stringent ethical publication standards, but may not describe everything in the author instructions. Moreover, this study included only journals listed in PubMed and IndMED, and there are many good journals which may have been missed due to these inclusion criteria. A journal is finally as good as its editorial teams and peer reviewers, irrespective of its inclusion in various databases.

\section{Conclusion}

The present study assessed Indian biomedical journals on the instructions to authors provided on their websites to facilitate an ethical publication process. There are a number of lacunae in the instructions to authors in many Indian journals. The most important aspect that needs strengthening is a dedicated section for ethics. Assent of child participants, specific ethics guidelines to be followed, privacy and confidentiality, and clinical trial guidelines are also areas that require more attention and improvement. A clear explicit warning against the menace of plagiarism was also missing in many journals. To address this menace, the scientific society journals should budget for procuring plagiarism detecting software on a priority basis. The guidelines on data sharing were uniformly missing in all the journals, and it has still not caught the attention of Indian researchers in the clinical trial landscape. The number of retractions in the last five years suggests that there are valid reasons to strengthen ethics in the publication process in India.

Statement of Funding and Conflict of Interest: This study did not receive any funding and none of the authors has any conflict of interest. This study was submitted as a project for Post Graduate Diploma in Bioethics and Medical Ethics (PGDBEME) at Centre for Ethics, Yenepoya (Deemed University). 


\section{References}

1. Medical Council of India. Minimum qualifications for teachers in medical institutions regulations, 1998 (Amended up to May 2015) [cited 2015 Dec 21]. Available at http://www.mciindia.org/Rules-andRegulation/TEQREGULATIONS-16.05.15.pdf

2. Aggarwal R, Gogtay N, Kumar R, Sahni P. The revised guidelines of the Medical Council of India for academic promotions: Need for a rethink. $J$ Family Med Prim Care. 2015 Oct;4(4):483.

3. Hemami S, Sharma G. Publication etiquette and ethics: Things you should know before submitting your next paper. leee.org. Date unknown [cited 2019 Oct 31]. Available from http://www.ieee.org.sv/ files/politicayetica.pdf

4. Bavdekar SB, Gogtay NJ, Chavan R. Reporting ethical processes: survey of 'instructions to authors' provided by Indian journals. Indian J Med Sci. 2009;63 (6):260-2.

5. Bavdekar SB, Gogtay NJ, Wagh S. Reporting ethical processes in two Indian journals. . Indian J Med Sci. 2008;62(4):134-40.

6. Belhekar MN, Bhalerao SS, Munshi RP. Ethics reporting practices in clinical research publications: A review of four Indian journals. Perspect Clin Res. 2014;5(3):129-33.

7. Jaykaran, Yadav P, Chavda N, Kantharia ND. Survey of "instructions to authors" of Indian medical journals for reporting of ethics and authorship criteria. Indian J Med Ethics.2011 Jan-Mar;8(1):36-8.

8. IndMED. Selection of Journals for Indexing IndMED. National Informatics Centre. Date unknown [cited 2017 Aug10]. Available from: http://medind.nic.in/imvw/

9. Balhara Y. Indexed journal: what does it mean? Lung India. $2012 \mathrm{Apr}$ Jun;29(2):193.DOI:10.4103/0970-2113.95345

10. Bolshete P. Authorship criteria and reporting of ethical compliance in Indian biomedical journals. Indian J Med Ethics. 2017 Jul-Sep;2(3):160-4. doi: 10.20529/IJME.2017.039

11. Indian Council of Medical Research. National Ethical Guidelines for Biomedical and Health Research involving Human Participants. New Delhi: ICMR;2017 Oct[cited 2017 Oct 15]. Available from:http://icmr.nic. in/guidelines/ICMR_Ethical_Guidelines_2017.pdf

12. Pereira S, Veeraraghavan $P, G$ hosh $S, G a n d h i$ M. Animal experimentation and ethics in India: the CPCSEA makes a difference. Alternatives to laboratory animals (ATLA). Fourth World Congress. 2004;32 Suppl 1B:411-5.

13. Atlas MC. Emerging ethical issues in instructions to authors of highimpact biomedical journals. Journal of the Medical Library Association: JMLA. 2003 Oct 1;91(4):442-9.

14. Henley L. Reporting ethical processes in journals. Indian J Med Sci. 2008 Apr 1;62(4):127.

15. World Medical Association. World Medical Association Declaration of Helsinki - Ethical principles for medical research involving human subjects. Bull World Health Organ. 2001;79(4):373-4.

16. Asai T, Shingu K. Ethical considerations in anaesthesia journals. Anaesthesia. 1999 Feb;54(2):192-7.

17. Molyneux CS, Wassenaar DR, Peshu N, Marsh K.'Even if they ask you to stand by a tree all day, you will have to do it (laughter)...!': Community voices on the notion and practice of informed consent for biomedical research in developing countries. Social Sci Med (1982). 2005 Jul;61(2):443-54.

18. Manti S, Licaria A. How to obtain informed consent for research. Breathe (Sheff). 2018 Jun; 14(2): 145-52. doi: 10.1183/20734735.001918

19. Baines P. Assent for children's participation in research is incoherent and wrong. Arch Dis Child. 2011 Jul; 96(10):960-2.

20. Sibley A, Sheehan M, Pollard AJ. Assent is not consent. J Med Ethics. 2012;38(1):3.
21. International Committee of Medical Journal Editors. Recommendations for the Conduct, Reporting, Editing and Publication of Scholarly Work in Medical Journals, December 2017. Available from http://icmje.org/ icmje-recommendations.pdf

22. International Committee of Medical Journal Editors. Journals following the ICMJE Recommendations. Available from http://www.icmje.org/ journals-following-the-icmje-recommendations/.2017 [cited 2017 Oct 30].

23. Matheson A. How industry uses the ICMJE guidelines to manipulate authorship--and how they should be revised. PLOS Med. 2011;8 (8):e1001072

24. American Association of University Professors Statement on Plagiarism.1990 jun[cited 2018 Aug 26]. Available from: http://ethics. iit.edu/ecodes/node/3173

25. Moylan EC, Kowalczuk MK. Why articles are retracted: a retrospective cross-sectional study of retraction notices at BioMed Central.BMJ Open. 2016 Nov;6(11):e012047.

26. Fang FC, Steen RG, Casadevall A. Misconduct accounts for the majority of retracted scientific publications. Proceedings of the National Academy of Sciences of the United States of America. 2012 Oct 16;109(42):17028-33.

27. Singh HP, Guram N. Knowledge and attitude of dental professionals of north India toward plagiarism. N Am J Med Sci. 2014 Jan;6(1):6-11.

28. Pupovac V, Fanelli D. Scientists Admitting to Plagiarism: A Meta-analysis of Surveys. Sci Eng Ethics. 2015 Oct 21;21(5):1331-52.

29. Bhandarkar D. Simultaneous submission leading to duplicate publication: Scientific misconduct rears its ugly head. J Minim Access Surg. 2013 Oct-Dec;9(4):147-8.

30. Rowan-Legg A, Weijer C, Gao J, Fernandez C. A comparison of journal instructions regarding institutional review board approval and conflictof-interest disclosure between 1995 and 2005. J Med Ethics2009 Jan;35(1):74-8

31. Satyanarayana K, Sharma A, Parikh P, Vijayan VK, Sahu DK, Nayak BK, Gulati RK, Parikh MN, Singh PP, Bavdekar SB, Sreehari U, Sahni P. Statement on publishing clinical trials in Indian biomedical journals. Natl Med J India. 2008May-Jun;21(3):105-6.

32. Yee A. Regulation failing to keep up with India's trials boom. Lancet. 2012; 379(9814):397-8.

33. Bhan A. Clinical trial ethics in India: One step forward, two steps back. $J$ Pharmacol Pharmacother. 2012;3(2):95-7.

34. Taichman DB, Backus J, Baethge $C$, Bauchner $H$, de Leeuw PW, Drazen JM, Fletcher J, Frizelle FA, Groves T, Haileamlak A, James A, Laine C, Peiperl L, Pinborg A, Sahni P, Wu S.. Sharing clinical trial data: a proposal from the International Committee of Medical Journal Editors. Lancet.. 2016;387(10016):e9-e11.

35. Kavsak PA. The International Committee of Medical Journal Editors proposal for sharing clinical trial data and the possible implications for the peer review process. Ann Transl Med. 2016 Mar;4(6):115.

36. Committee on Publication Ethics. Promoting Integrity in Research Publications. Date unknown [cited 2017 Oct 30] Available from:. http:// publicationethics.org/.2016

37. Bourke-Waite A. Retractions from Springer and BioMed Central journals. Springer Nature. Available from: https://www.biomedcentral. com/about/press-centre/business-press-releases/01-11-16

38. Bohannon J. Scientific publishing. Hoax-detecting software spots fake papers. Science. 2015 Apr 3;348(6230):18-9.

39. Bohannon J. Who's afraid of peer review? Science. 2013 Oct 4;342(6154):60-5. 